\title{
Temporal Trends in Racial and Ethnic Disparities in Sleep Duration in the United States:
}

\section{A National Health Interview Survey Analysis from 2004-2018}

Short title: Trends in Racial and Ethnic Disparities in Sleep Duration

César Caraballo, MD; ${ }^{1,2}$ Shiwani Mahajan, MBBS, MHS; ${ }^{1,3}$ Javier Valero-Elizondo, MD, MPH; ${ }^{4,5}$ Daisy Massey, BA; ${ }^{1}$ Yuan Lu, ScD; ${ }^{1,2}$ Brita Roy, MD, MPH, MHS; ${ }^{3,6}$ Carley Riley, MD, MPP, MHS; ${ }^{7,8}$ Amarnath R. Annapureddy, MD; ${ }^{2}$ Karthik Murugiah, MD; ${ }^{1,2}$ Johanna Elumn, MSW, PhD, BA $;^{9}$ Khurram Nasir, MD, MPH, MSc; ${ }^{4,5}$ Marcella Nunez-Smith, MD, MHS; ${ }^{10}$ Howard P. Forman, MD, MBA; ${ }^{11}$ Chandra L. Jackson, PhD, MS; ${ }^{12,13}$ Jeph Herrin, PhD; ${ }^{2}$ Harlan M. Krumholz, MD, SM ${ }^{1,2,14}$

${ }^{1}$ Center for Outcomes Research and Evaluation, Yale New Haven Hospital, New Haven, Connecticut

${ }^{2}$ Section of Cardiovascular Medicine, Department of Internal Medicine, Yale School of Medicine, New Haven, Connecticut

${ }^{3}$ Section of General Internal Medicine, Department of Internal Medicine, Yale School of Medicine, New Haven, Connecticut

${ }^{4}$ Division of Cardiovascular Prevention and Wellness, Houston Methodist DeBakey Heart and Vascular Center, Houston, Texas

${ }^{5}$ Center for Outcomes Research, Houston Methodist Research Institute, Houston, Texas

${ }^{6}$ Department of Chronic Disease Epidemiology, Yale School of Public Health, New Haven, Connecticut

${ }^{7}$ Department of Pediatrics, University of Cincinnati College of Medicine, Cincinnati, Ohio 
${ }^{8}$ Division of Critical Care Medicine, Cincinnati Children's Hospital Medical Center, Cincinnati, Ohio

${ }^{9}$ SEICHE Center for Health and Justice, Section of General Internal Medicine, Yale School of Medicine, New Haven, Connecticut

${ }^{10}$ Equity Research and Innovation Center, Section of General Internal Medicine, Yale School of Medicine, New Haven, Connecticut

${ }^{11}$ Department of Radiology and Biomedical Imaging, Yale School of Medicine, New Haven, Connecticut

${ }^{12}$ Epidemiology Branch, National Institute of Environmental Health Sciences, National Institutes of Health, Department of Health and Human Services, Research Triangle Park, North Carolina

${ }^{13}$ Intramural Program, National Institute on Minority Health and Health Disparities, National Institutes of Health, Department of Health and Human Services, Bethesda, Maryland

${ }^{14}$ Department of Health Policy and Management, Yale School of Public Health, New Haven, Connecticut

\section{Corresponding author:}

Harlan M. Krumholz, MD, SM

195 Church Street, Fifth Floor, New Haven, CT, 06510

Phone: 203-497-1246

Email: harlan.krumholz@yale.edu

Word count: 3526 


\section{KEY POINTS}

Question: How have racial and ethnic differences in self-reported sleep duration among US adults changed between 2004 and $2018 ?$

Findings: In this serial cross-sectional study that included 429,195 adults, the prevalence of unrecommended sleep duration was persistently higher among Black individuals over the 15year study period. These disparities were highest for Black women, Black individuals with middle or high income, and young and middle-aged Black adults.

Meaning: There were marked racial and ethnic differences in sleep duration that persisted from 2004 to 2018, which may be contributing to health disparities. 


\section{ABSTRACT}

Importance: Minoritized racial and ethnic groups are generally more likely to experience sleep deficiencies. It is unclear how these sleep duration disparities have changed over recent years.

Objective: To determine 15-year trends in the racial and ethnic differences in self-reported sleep duration among adults in the US.

Design: Serial cross-sectional study.

Setting: National Health Interview Survey from years 2004-2018.

Participants: 429,195 non-institutionalized adults.

Exposures: Self-reported race, ethnicity, household income, and sex/gender.

Main Outcomes: Temporal trends and racial/ethnic differences in short- and long-sleep duration ( $\leq 6$ and $\geq 10$ hours in a 24 -hour period, respectively) and racial/ethnic differences in the relationship between sleep duration and age.

Results: The study sample consisted of 429,195 individuals (mean age 46.5 [SE, 0.08] years; $51.7 \%$ female) of which $5.1 \%$ identified as Asian, $11.8 \%$ as Black, $14.7 \%$ as Latino/Hispanic, and $68.5 \%$ as White. In 2004, the adjusted estimated prevalence of short-sleep duration and longsleep duration, respectively, were $31.3 \%$ and $2.5 \%$ among Asian individuals, $35.3 \%$ and 6.4\% among Black individuals, $27.0 \%$ and $4.6 \%$ among Latino/Hispanic individuals, and $27.8 \%$ and $3.5 \%$ among White individuals. Over the study period, there was a significant increase in the short sleep prevalence among Black, Latino/Hispanic, and White individuals ( $\mathrm{P} \leq 0.02$ for each), whereas prevalence of long sleep changed significantly only among Latino/Hispanic individuals (-1.4 points, $\mathrm{P}=0.01)$. In 2018, compared with White individuals, short sleep prevalence among Black and Latino/Hispanic individuals was higher by 10.7 points and 2.6 points, respectively ( $\mathrm{P} \leq 0.02$ each), and long sleep prevalence among Black people was significantly higher by 1.4 
points $(\mathrm{P}=0.01)$. These racial/ethnic disparities were the greatest among women and among those with middle/high household income. Over the study period, Black individuals younger than 60 years old had the highest prevalence of short sleep compared with those of the same age; and Black individuals had a higher long-sleep duration prevalence than White individuals across all age groups.

Conclusions: From 2004 to 2018, the prevalence of unrecommended sleep duration was persistently higher among Black individuals. The Black-White disparities were highest among women, individuals who had middle or high income, and among young or middle-aged adults. 


\section{BACKGROUND}

In the US, minoritized racial and ethnic groups are generally more likely to report and experience sleep deficiencies that may be drivers of racial and ethnic disparities in physical health, mental health, and quality of life. ${ }^{1-9}$ Both short and long-sleep duration are more prevalent among Black and Latino/Hispanic people compared with White people. ${ }^{10-14}$ These disparities in sleep have been reported for decades, ${ }^{15}$ and there has not been any progress in reducing them. The proportion of people reporting short-sleep duration has increased across different racial and ethnic groups, widening the gap between Black and White individuals from 2004 to $2017 .^{12}$ This occurred despite the Healthy People 2020 initiative that had as a national health objective to increase the proportion of people with sufficient sleep. ${ }^{16}$ Because such a goal was not achieved, it was reincluded in Healthy People 2030. ${ }^{17}$

In 2020, a joint effort by the National Institute on Minority Health and Health Disparities, the National Heart, Lung, and Blood Institute, and the Office of Behavioral and Social Sciences Research published a report addressing these sleep health disparities. ${ }^{8}$ They proposed a framework for sleep health disparities research that focused on the need for greater understanding of health consequences, and interventions that may eliminate them. This report underscores the need for a more detailed evaluation of the population-level trends in sleep health disparities.

Several key gaps in knowledge persist. First, though there is information on short sleep, our understanding on trends in long sleep, also a risk factor for adverse health outcomes, and overall suboptimal sleep that is not in the recommended range, remains poor. Moreover, there is little information on trends in the racial and ethnic disparities in sleep health stratified by age, sex/gender, or household income. ${ }^{15,18,19}$ For instance, an understanding of how racial and ethnic 
differences in sleep duration vary with age may illuminate the periods of a lifetime in which these disparities emerge and peak. A deeper understanding of the interactions between race and ethnicity, sex/gender, and household income is important to identify at-risk groups and institute effective interventions. Finally, many studies have not included Asian people as a distinct, albeit heterogenous, race group.

Accordingly, we describe the temporal trends in racial and ethnic disparities in sleep duration over 15 years using nationally representative data from the National Health Interview Survey (NHIS). We estimated differences in the reported short, long, or overall unrecommended sleep duration between racial and ethnic groups, also stratifying by sex/gender, household income, and health status. In addition, we evaluated the racial and ethnic differences in the relationship between sleep duration and age. The purpose of this study is to illuminate trends in racial/ethnic disparities in sleep duration to inform policies and practices designed to address these disparities.

\section{METHODS}

\section{Data Source}

We used data from the annual NHIS from 2004 to 2018. The NHIS has a complex multistage area probability design that accounts for non-response and oversampling of underrepresented groups, which allows for nationally representative estimates (details in eMethods). ${ }^{20}$ We used data from the Sample Adult Core file (includes responses from one adult who is randomly selected from each family for a more in-depth questionnaire), which had a mean conditional and final response rate during the study period of $80.3 \%$ and $62.1 \%$, respectively (eMethods). We obtained the harmonized data from the Integrated Public Use Microdata Series Health Surveys 
(https://nhis.ipums.org/). ${ }^{21}$ The Institutional Review Board at Yale University exempted the study from review as NHIS data are publicly available. The code used to analyze these data is publicly available at https://doi.org/10.3886/E152741V1.

\section{Study Population}

We included individuals $\geq 18$ years old from years 2004 to 2018 of the NHIS. We excluded respondents with missing sleep data. Due to small numbers, we also excluded those who did not identify as Latino/Hispanic and identified as Alaskan Native, American Indian, or did not select a primary race (details in Results section).

\section{Demographic Variables}

Participants were classified into 4 mutually exclusive subgroups: non-Hispanic Asian (Asian), non-Hispanic Black/African American (Black), Latino/Hispanic, and non-Hispanic White (White), based on their responses to the questions "What race do you consider yourself to be?" and “Do you consider yourself Latino/Hispanic?”. Other characteristics included were selfreported age, sex/gender (male or female), household income level, health status, and geographic region (Northeast, North Central/Midwest, South, West). Based on the family income level relative to the respective year's federal poverty level from the US Census Bureau, income level was categorized as low income $(<200 \%)$ or middle/high income $(\geq 200 \%) .{ }^{22-24}$ In the NHIS, health status was assessed on a 5-point scale (excellent, very good, good, fair, or poor) based on an individual's self-perceived general health. For this study, responses were dichotomized into poor or fair health status vs good to excellent health. Other clinical and sociodemographic characteristics were used only to describe the study population (eMethods). 


\section{Sleep Duration}

In the NHIS, participants were asked "On average, how many hours of sleep do you get in a 24hour period?" We defined recommended sleep duration as 7 to 9 hours of sleep in a 24-hour period, short sleep as reporting sleeping 6 or fewer hours, and long-sleep duration as reporting 10 or more hours, consistent with expert consensus recommendations. ${ }^{25}$ Additionally, we defined unrecommended sleep duration as a composite measure of either short or long-sleep duration (i.e., $\leq 6$ or $\geq 10$ hours).

\section{Statistical Analysis}

We first described the general characteristics of the study population. For each year, we estimated the short, long, and unrecommended sleep duration prevalence for each racial/ethnic group using separate multivariable logistic regression models, adjusting for age and region (details in eMethods). To measure the racial and ethnic differences in short, long, and unrecommended sleep duration, we subtracted the annual prevalence among White people from the annual prevalence among Asian, Black, and Latino/Hispanic people for that year. Using these annual estimates and differences between estimates, we determined trends over the study period by fitting weighted linear regression models. In a separate analysis, we tested for an absolute difference in each sleep duration outcome (short, long, or unrecommended) prevalence within each race and ethnic group, and the differences between groups, between 2004 and 2018 using a Z-test.

To evaluate the association between race and ethnicity and each of these sleep duration outcomes by age, we used logistic regression models with each sleep duration outcome as the dependent variable and age group as the independent variable (eMethods). 
We then stratified the main analysis described above by sex/gender and household income, separately. Due to the high amount of missing income information from non-response, our income-stratified analysis was performed based on the National Center for Health Statistics recommendations for multiply imputed data analysis (eMethods). ${ }^{26}$ Finally, as a supplementary analysis, we stratified the main temporal trends analysis by health status to explore the extent to which the sleep disparities were explained by racial and ethnic differences in self-perceived health.

For all analyses, a 2 -sided P-value $<0.05$ was used to determine statistical significance. All analyses were performed using Stata SE version 17.0 (StataCorp) and incorporated strata and weights to produce nationally representative estimates using the -svy-family of commands for structured survey data. All results are reported with 95\% CIs. All person weights were pooled and divided by the number of years studied, following guidance from the NHIS. ${ }^{27}$

\section{RESULTS}

\section{Population Characteristics}

From 444,743 adults interviewed from 2004 to 2018, we excluded 10,203 (2.3\%) who had missing information on sleep duration. Because of small numbers, we also excluded 3440 individuals who identified as Alaskan Native or American Indian and 1905 individuals who did not select a primary race (eFigure 1). Thus, the study sample consisted of 429,195 individuals (mean age 46.5 [SE, 0.08] years; $51.7 \%$ [95\% CI: 51.5, 51.9] female) of which $5.1 \%$ (95\% CI: 4.9, 5.2) identified as Asian, $11.8 \%$ (95\% CI: 11.5, 12.2) identified as Black, $14.7 \%$ (95\% CI: 14.2, 15.1) identified as Latino/Hispanic, and 68.5\% (95\% CI: 67.9, 69.0) identified as White. 
Study population characteristics are shown in Table 1, and the unadjusted sleep duration distribution by race and ethnicity is shown in eFigure 2.

\section{Temporal Trends over the Study Period from 2004 to 2018}

\section{Short-Sleep Duration}

In 2004, the age- and region-adjusted estimated prevalence of short sleep was $31.3 \%$ among Asian individuals, 35.3\% among Black individuals, 27.0\% among Latino/Hispanic individuals, and 27.8\% among White individuals (Figure 1). From 2004 to 2018, the prevalence of short sleep significantly increased among Black, Latino/Hispanic, and White people regardless of sex/gender or household income stratum ( $\mathrm{P} \leq 0.02$ for each), but not among Asian people (Table 2). The annualized rate of change is shown in eTable 1. In the same period, the difference between White and Latino/Hispanic individuals increased significantly $(\mathrm{P}=0.02)$ but did not change significantly between the other subgroups. In 2018, compared with the estimated prevalence among White individuals (31.0\%), short-sleep duration among Black and Latino/Hispanic individuals was higher by 10.7 points $(\mathrm{P}<0.001)$ and 2.6 points $(\mathrm{P}=0.02)$, respectively (Table 2).

During the study period, the prevalence difference between Black women and White women persisted and was +12.1 points $(\mathrm{P}<0.001)$ in 2018 ; among men in 2018, the Black-White gap was +9.1 points $(\mathrm{P}<0.001)$. The prevalence difference between Latino/Hispanic men and White men increased by 6.1 points $(\mathrm{P}=0.004)$ reaching a difference of +3.8 points $(\mathrm{P}=0.03)$ in

\section{8 (Figure 1 and Table 2).}

When stratified by income, Black individuals consistently had the highest prevalence of short sleep over the study period (Figure 1). In 2018, the difference between Black individuals 
and White individuals was greater among those with middle/high income than among those with low income; and low-income Latino/Hispanic individuals had a lower short-sleep prevalence than low-income White individuals (Table 2). The differences in 2018 between White and Asian individuals were not significant, regardless of income level.

\section{Long-Sleep Duration}

In 2004, the adjusted estimated prevalence of long sleep was $2.5 \%$ among Asian individuals, 6.4\% among Black individuals, $4.6 \%$ among Latino/Hispanic individuals, and 3.5\% among White individuals (Figure 2). From 2004 to 2018, the prevalence of long sleep decreased among Latino/Hispanic people by 1.4 percent points $(\mathrm{P}=0.01)$, with no significant change in the prevalence among other subgroups (Table 2). In 2018, compared with the estimated long-sleep

prevalence among White individuals (3.7\%), prevalence among Black people was higher by 1.4 points $(\mathrm{P}=0.01)$. Compared with White women, Black women had higher prevalence of long sleep during the study period (Figure 2). When stratified by income, the 2018 difference between White and Black individuals was no longer significant (Figure 2).

\section{Unrecommended Sleep Duration: Composite of Short- and Long-Sleep Duration}

In 2004, the adjusted estimated prevalence of unrecommended sleep duration (short or long sleep) was 34.2\% among Asian individuals, 41.9\% among Black individuals, 31.6\% among Latino/Hispanic individuals, and 31.7\% among White individuals (eFigure 3). From 2004 to 2018, the prevalence of unrecommended sleep duration increased for all groups except Asian individuals (eTable 2). In 2018, unrecommended sleep duration was 12.0 percent points more prevalent among Black individuals compared with White individuals $(\mathrm{P}<0.001)$. Such a 
difference remained significant regardless of sex/gender or household income stratum (eFigure 3), although it was the highest for Black women (+13.8 points, $\mathrm{P}<0.001)$ and for Black individuals with middle/high income $(+11.6$ points, $\mathrm{P}<0.001)$. In addition, among those with middle/high income, unrecommended sleep duration prevalence was 4.1 points higher $(\mathrm{P}=0.01)$ among Latino/Hispanic individuals than among White individuals in 2018.

Supplementary Analysis: Stratification by Health Status

When stratified by health status, the prevalences of both short- and long-sleep duration were generally higher among individuals with poor or fair health, and the observed racial and ethnic disparities in each measure persisted within each health status stratum over the study period (eTables 3 and 4 and eFigures 4 and 5 ).

\section{Differences in the Relationship Between Sleep Duration and Age}

\section{Short-Sleep Duration}

Over the study period, Black people younger than 60 years had the highest prevalence of short sleep compared with those of the same age (Figure 3), with a difference with White individuals of +6.9 points among those $18-24$ years and +10.7 points among those aged $50-59$ years. Compared with White individuals, prevalence among Asian and Latino/Hispanic individuals was lower among those older than 50 years, eventually surpassing White individuals among those older than 60 years. Among those older than 65 years, the prevalence of short-sleep duration decreased for all subgroups as age increased. Similar patterns were observed by sex/gender (eFigure 6). When stratified by household income, the prevalence among Black and White 
individuals with low income were consistently similar among those younger than 55 years, widening among those who were older (eFigure 6).

\section{Long-Sleep Duration}

Across all race/ethnicity groups, prevalence of long sleep was lower among those between 30 to 60 years old. With the exception of individuals aged 18-24 years, Black individuals had a higher prevalence than White individuals across all age groups, ranging from +1.7 points among those aged $30-35$ years to +3.8 points among those aged $\geq 80$ years (Figure 3 ). The Black-White gap across age groups was slightly higher among women compared with men (eFigure 7). When stratified by income, prevalence was higher among Black compared with White individuals (eFigure 7).

\section{Unrecommended Sleep Duration}

Overall, Black individuals had the highest prevalence of unrecommended sleep duration across all age groups (eFigure 8), although overlapping with estimates among Asian and Latino/Hispanic individuals aged 65 years and older. Compared with White individuals, the prevalence of unrecommended sleep duration among Black individuals was higher by 7.7 points among those aged 18-24 years, increasing with age up to its maximum of +13.3 points among those aged 60-64 years. These differences were greater among women and among individuals with middle/high income (eFigure 8).

\section{DISCUSSION}


In this nationally representative sample from 2004 to 2018, there was increasing prevalence of unrecommended sleep duration with persistence of racial and ethnic differences. Black individuals consistently had the highest prevalence of unrecommended sleep duration, reaching a difference of 12 percent points compared with White individuals in 2018. The disparities were largest for Black women and Black individuals with middle/high income. In addition, the proportion of Latino/Hispanic individuals who reported short sleep increased among men, widening their gap with White men to nearly 4 percent points in 2018. Prevalence among Asian individuals did not change significantly in the 15 -year period and was not significantly different from that of White individuals. Notably, when analyzed by age, the racial and ethnic disparities were greatest among young and middle-aged Black adults and slightly narrowed among the elderly.

This study expands the literature in several ways. First, we used data from 2004 to 2018 to describe trends in racial and ethnic disparities in sleep duration. Our findings regarding short sleep are consistent with a recent study, ${ }^{12}$ expanding them by analyzing disparities in long and unrecommended sleep duration as well as by quantifying the magnitude and significance of change in these racial and ethnic differences over the past 15 years. Second, we assessed the racial and ethnic differences in the association between each of these sleep duration outcomes and age. To the best of our knowledge, this has not been described before. Third, we stratified our findings by sex/gender and income, providing further insight in the characterization of these disparities. Fourth, we stratified by health status and found persistence in the disparities. Finally, we included Asian people in our analyses, finding that their estimates remained stable, without substantial differences with White individuals in 2018. 
To understand why unrecommended sleep duration may be more common among Black people, it is important to discuss the influence of psychosocial stressors, such as race-based discrimination, on sleep health. The stress from perceived race-based discrimination (and its anticipation or vigilance) contributes to poor sleep duration and quality, ${ }^{28}$ and Black people in the US are more likely to experience this than other racial or ethnic groups. Furthermore, the effect of perceived discrimination on sleep duration is greater among Black women than among Black men, ${ }^{29}$ which could partially explain our findings in which the racial gaps were the widest among Black women.

The fact that the disparities were the widest among young and middle-aged adults may inform that factors related to working or employment conditions might be disproportionally preventing Black individuals from having adequate sleep. ${ }^{30}$ Notably, when analyzed by age, the gap between Black and White individuals with low income was substantially narrower compared with the gap among those with middle or high income. This suggests that a higher income may prevent White people from experiencing unrecommended sleep but does not have such a protective association among Black people. This differential effect of income on sleep health is consistent with observations that higher educational attainment and professional responsibility is associated with lower odds of short sleep among White adults, and with greater odds among Black and Latino/Hispanic adults. ${ }^{31-33}$ It is possible that income in our study is an indicator of educational and professional attainment, and that Black individuals with higher income are more commonly exposed to stressors preventing adequate sleep, including higher racial discrimination. ${ }^{34}$

This study has limitations. We relied on self-reported duration of sleep, which may be subject to recall and social desirability bias. Of note, across racial and ethnic groups, self- 
reported sleep has shown a low-to-moderate agreement with objective sleep duration measurement. ${ }^{35-38}$ However, self-reported sleep duration has important health implications, including consistent association with mortality across different populations. ${ }^{39-42}$ Additionally, for the entire study period, we lacked other information that may have provided a more in-depth understanding of these disparities, such as quality of sleep, other sleep duration alterations, and medications that may alter sleep pattern and duration.

Our findings have important public health implications. These persistent disparities may contribute to other persistent racial and ethnic disparities in health. A study indicated that from 1999 to 2018 , Black people had the highest prevalence of poor or fair health. ${ }^{24}$ Although the cross-sectional nature of these two studies prevent us from assessing causality, there is ample evidence that unrecommended sleep can cause detriments in health. People with short or long sleep are at increased risk of depression, reduced quality of life, cardiovascular disease, diabetes, and death, among other conditions. ${ }^{42-45}$ Such a persistent gap in sleep duration may thus be a cause and exacerbator of other health disparities, and may serve as an imperfect indicator of overall disparities in health and well-being. For the national objective of achieving health equity, understood as the assurance of the condition of optimal health for all people, ${ }^{46}$ it is thus instrumental to also strive for the elimination of socioeconomic and health conditions that prevent racial and ethnic minorities from achieving adequate sleep.

Our findings also have important implications for the design of public health interventions, suggesting that targeted efforts should be made to improve sleep health among Black individuals. The observed persistent—and growing — disparities in sleep duration serve as an additional indicator of the consequences of the artificial racial and ethnic hierarchy in which people of color encounter higher barriers to maintaining a healthy life, including income 
distribution inequality, racial segregation, restricted access to medical care, and exposure to social and environmental conditions that affect health and sleep such as light, noise, and air pollution. Thus, and as with other disparities, public policies may be ineffective in eliminating these racial and ethnic disparities in sleep without accounting for systemic racism as a fundamental cause.

In conclusion, from 2004 to 2018, there were significant differences in sleep duration by race and ethnicity, and the prevalence of unrecommended sleep duration was persistently higher among Black individuals. The disparities were highest for Black women, Black individuals who had middle or high income, and young and middle-aged Black adults. Given the importance of sleep to health, the prevalence of unrecommended sleep duration could be a contributor to health disparities. 


\section{REFERENCES}

1. St-Onge MP, Grandner MA, Brown D, et al. Sleep Duration and Quality: Impact on Lifestyle Behaviors and Cardiometabolic Health: A Scientific Statement From the American Heart Association. Circulation. 2016;134(18):e367-e386. doi:10.1161/cir.0000000000000444

2. Tobaldini E, Fiorelli EM, Solbiati M, Costantino G, Nobili L, Montano N. Short sleep duration and cardiometabolic risk: from pathophysiology to clinical evidence. Nat Rev Cardiol. 2019;16(4):213-224. doi:10.1038/s41569-018-0109-6

3. Liu Y, Wheaton AG, Croft JB, Xu F, Cunningham TJ, Greenlund KJ. Relationship between sleep duration and self-reported health-related quality of life among US adults with or without major chronic diseases, 2014. Sleep Health. 2018/06/01/ 2018;4(3):265-272. doi:https://doi.org/10.1016/j.sleh.2018.02.002

4. Itani O, Jike M, Watanabe N, Kaneita Y. Short sleep duration and health outcomes: a systematic review, meta-analysis, and meta-regression. Sleep Medicine. 2017/04/01/ 2017;32:246-256. doi:https://doi.org/10.1016/j.sleep.2016.08.006

5. Goldstein SJ, Gaston SA, McGrath JA, Jackson CL. Sleep health and serious psychological distress: a nationally representative study of the United States among white, black, and hispanic/latinx adults. Nat Sci Sleep. 2020;12:1091-1104. doi:10.2147/nss.S268087

6. Buxton OM, Marcelli E. Short and long sleep are positively associated with obesity, diabetes, hypertension, and cardiovascular disease among adults in the United States. Soc Sci Med. Sep 2010;71(5):1027-36. doi:10.1016/j.socscimed.2010.05.041

7. Jike M, Itani O, Watanabe N, Buysse DJ, Kaneita Y. Long sleep duration and health outcomes: A systematic review, meta-analysis and meta-regression. Sleep Med Rev. 2018;39:2536. doi:10.1016/j.smrv.2017.06.011 
medRxiv preprint doi: https://doi.org/10.1101/2021.10.31.21265202; this version posted November 1, 2021. The copyright holder for this preprint (which was not certified by peer review) is the author/funder, who has granted medRxiv a license to display the preprint in perpetuity.

It is made available under a CC-BY-NC-ND 4.0 International license .

8. Jackson CL, Walker JR, Brown MK, Das R, Jones NL. A workshop report on the causes and consequences of sleep health disparities. Sleep. 2020;43(8)doi:10.1093/sleep/zsaa037

9. Johnson DA, Jackson CL, Williams NJ, Alcántara C. Are sleep patterns influenced by race/ethnicity - a marker of relative advantage or disadvantage? Evidence to date. Nat Sci Sleep. 2019;11:79-95. doi:10.2147/nss.S169312

10. Chen X, Wang R, Zee P, et al. Racial/ethnic differences in sleep disturbances: the MultiEthnic Study of Atherosclerosis (MESA). Sleep. 2015;38(6):877-88. doi:10.5665/sleep.4732

11. Khubchandani J, Price JH. Short sleep duration in working American adults, 2010-2018. J Community Health. 2020;45(2):219-227. doi:10.1007/s10900-019-00731-9

12. Sheehan CM, Frochen SE, Walsemann KM, Ailshire JA. Are U.S. adults reporting less sleep?: Findings from sleep duration trends in the National Health Interview Survey, 2004-2017. Sleep. 2019;42(2)doi:10.1093/sleep/zsy221

13. Krueger PM, Friedman EM. Sleep duration in the United States: a cross-sectional population-based study. Am J Epidemiol. 2009;169(9):1052-63. doi:10.1093/aje/kwp023

14. Jean-Louis G, Grandner MA, Youngstedt SD, et al. Differential increase in prevalence estimates of inadequate sleep among black and white Americans. BMC Public Health.

2015;15:1185. doi:10.1186/s12889-015-2500-0

15. Stamatakis KA, Kaplan GA, Roberts RE. Short sleep duration across income, education, and race/ethnic groups: population prevalence and growing disparities during 34 years of followup. Ann Epidemiol. 2007/12/01/ 2007;17(12):948-955.

doi:https://doi.org/10.1016/j.annepidem.2007.07.096

16. U.S. Department of Health and Human Services. Healthy People 2020. Accessed October 20, 2021. https://www.healthypeople.gov/2020/topics-objectives/topic/sleep-health 
medRxiv preprint doi: https://doi.org/10.1101/2021.10.31.21265202; this version posted November 1, 2021. The copyright holder for this preprint (which was not certified by peer review) is the author/funder, who has granted medRxiv a license to display the preprint in perpetuity.

It is made available under a CC-BY-NC-ND 4.0 International license .

17. U.S. Department of Health and Human Services. Healthy People 2030. Accessed October

20, 2021. https://health.gov/healthypeople/objectives-and-data/browse-objectives/sleep

18. Jackson CL, Powell-Wiley TM, Gaston SA, Andrews MR, Tamura K, Ramos A.

Racial/ethnic disparities in sleep health and potential interventions among women in the United

States. J Womens Health (Larchmt). 2020;29(3):435-442. doi:10.1089/jwh.2020.8329

19. Whinnery J, Jackson N, Rattanaumpawan P, Grandner MA. Short and long sleep duration associated with race/ethnicity, sociodemographics, and socioeconomic position. Sleep. 2014;37(3):601-611. doi:10.5665/sleep.3508

20. Centers for Disease Control and Prevention. About the National Health Interview Survey. 2019. Updated accessed October 20, 2021. https://www.cdc.gov/nchs/nhis/about nhis.htm

21. Blewett LA, Rivera Drew JA, King ML, and Williams KCW. IPUMS health surveys:

National Health Interview Survey, version 6.4 [dataset]. Minneapolis, MN: IPUMS, 2019.

Accessed March 16, 2021. https://doi.org/10.18128/D070.V6.4

22. Caraballo C, Valero-Elizondo J, Khera R, et al. Burden and consequences of financial hardship from medical bills among nonelderly adults with diabetes mellitus in the United States. Circ Cardiovasc Qual Outcomes. 2020;13(2):e006139. doi:10.1161/circoutcomes.119.006139

23. Dubay LC, Lebrun LA. Health, behavior, and health care disparities: disentangling the effects of income and race in the United States. Int J Health Serv. 2012;42(4):607-25. doi:10.2190/HS.42.4.c

24. Mahajan S, Caraballo C, Lu Y, et al. Trends in differences in health status and health care access and affordability by race and ethnicity in the United States, 1999-2018. JAMA. 2021;326(7):637-648. doi:10.1001/jama.2021.9907 
25. American Academy of Sleep Medicine and Sleep Research Society. Recommended amount of sleep for a healthy adult: a joint consensus statement. Sleep. 2015;38(6):843-844. doi:10.5665/sleep.4716

26. Division of Health Interview Statistics, National Center for Health Statistics. Multiple imputation of family income and personal earnings in the National Health Interview Survey: methods and examples. August 2019. Accessed October 20, 2021. https://nhis.ipums.org/nhis/resources/tecdoc18.pdf

27. Centers for Disease Control and Prevention. National Health Interview Survey, 19972018. Survey description document. Accessed October 20, 2021. https://www.cdc.gov/nchs/nhis/1997-2018.htm

28. Gaston SA, Feinstein L, Slopen N, Sandler DP, Williams DR, Jackson CL. Everyday and major experiences of racial/ethnic discrimination and sleep health in a multiethnic population of U.S. women: findings from the Sister Study. Sleep Med. 2020/07/01/ 2020;71:97-105. doi:https://doi.org/10.1016/j.sleep.2020.03.010

29. Sims M, Diez-Roux AV, Gebreab SY, et al. Perceived discrimination is associated with health behaviours among African-Americans in the Jackson Heart Study. J Epidemiol Community Health. 2016;70(2):187-94. doi:10.1136/jech-2015-206390

30. Grandner MA, Williams NJ, Knutson KL, Roberts D, Jean-Louis G. Sleep disparity, race/ethnicity, and socioeconomic position. Sleep Med. 2016;18:7-18.

doi:10.1016/j.sleep.2015.01.020

31. Luo L, Buxton OM, Gamaldo AA, Almeida DM, Xiao Q. Opposite educational gradients in sleep duration between Black and White adults, 2004-2018. Sleep Health. 2021;7(1):3-9. doi:10.1016/j.sleh.2020.10.003 
32. Sheehan CM, Walsemann KM, Ailshire JA. Race/ethnic differences in educational gradients in sleep duration and quality among U.S. adults. SSM Popul Health. 2020;12:100685. doi:10.1016/j.ssmph.2020.100685

33. Jackson CL, Redline S, Kawachi I, Williams MA, Hu FB. Racial disparities in short sleep duration by occupation and industry. Am J Epidemiol. 2013;178(9):1442-51. doi:10.1093/aje/kwt159

\section{Mouzon DM, Taylor RJ, Nguyen AW, Ifatunji MA, Chatters LM. Everyday}

Discrimination typologies among older african americans: gender and socioeconomic status. $J$ Gerontol: Series B. 2019;75(9):1951-1960. doi:10.1093/geronb/gbz088

35. Cespedes EM, Hu FB, Redline S, et al. Comparison of self-reported sleep duration with actigraphy: results from the hispanic community health study/study of latinos sueño ancillary study. Am J Epidemiol. 2016;183(6):561-73. doi:10.1093/aje/kwv251

36. Lauderdale DS, Knutson KL, Yan LL, Liu K, Rathouz PJ. Self-reported and measured sleep duration: how similar are they? Epidemiology. 2008;19(6):838-45.

doi:10.1097/EDE.0b013e318187a7b0

37. Jackson CL, Patel SR, Jackson WB, 2nd, Lutsey PL, Redline S. Agreement between selfreported and objectively measured sleep duration among white, black, Hispanic, and Chinese adults in the United States: Multi-Ethnic Study of Atherosclerosis. Sleep. 2018;41(6)doi:10.1093/sleep/zsy057

38. Jackson CL, Ward JB, Johnson DA, Sims M, Wilson J, Redline S. Concordance between self-reported and actigraphy-assessed sleep duration among African-American adults: findings from the Jackson Heart Sleep Study. Sleep. 2020;43(3)doi:10.1093/sleep/zsz246 
39. Tamakoshi A, Ohno Y. Self-reported sleep duration as a predictor of all-cause mortality: results from the JACC study, Japan. Sleep. 2004;27(1):51-4.

40. Kwok CS, Kontopantelis E, Kuligowski G, et al. Self-reported sleep duration and quality and cardiovascular disease and mortality: a dose-response meta-analysis. J Am Heart Assoc. 2018;7(15):e008552. doi:doi:10.1161/JAHA.118.008552

41. Kronholm E, Laatikainen T, Peltonen M, Sippola R, Partonen T. Self-reported sleep duration, all-cause mortality, cardiovascular mortality and morbidity in Finland. Sleep Med. 2011/03/01/ 2011;12(3):215-221. doi:https://doi.org/10.1016/j.sleep.2010.07.021

42. Svensson T, Saito E, Svensson AK, et al. Association of sleep duration with all- and major-cause mortality among adults in Japan, China, Singapore, and Korea. JAMA Network Open. 2021;4(9):e2122837-e2122837. doi:10.1001/jamanetworkopen.2021.22837

43. Liu T-Z, Xu C, Rota M, et al. Sleep duration and risk of all-cause mortality: a flexible, non-linear, meta-regression of 40 prospective cohort studies. Sleep Med Rev. 2017/04/01/ 2017;32:28-36. doi:https://doi.org/10.1016/j.smrv.2016.02.005

44. Gallicchio L, Kalesan B. Sleep duration and mortality: a systematic review and metaanalysis. J Sleep Res. 2009;18(2):148-158. doi:https://doi.org/10.1111/j.1365-2869.2008.00732.x 45. Medic G, Wille M, Hemels ME. Short- and long-term health consequences of sleep disruption. Nat Sci Sleep. 2017;9:151-161. doi:10.2147/nss.S134864

46. Keenan W, Sanchez CE, Kellogg E, et al. Achieving behavioral health equity for children, families, and communities: Proceedings of a Workshop. Washington (DC): National Academies Press (US); 2019 Feb 13. 2, Introduction to Health Equity and Social Determinants of Health. Available from: https://www.ncbi.nlm.nih.gov/books/NBK540766/. 


\section{ACKNOWLEDGEMENTS}

SOURCE OF FUNDING: This research was funded, in part, by the Intramural Program at the National Institutes of Health, National Institute of Environmental Health Sciences (Z1AES103325-01).

CONFLICTING INTERESTS DISCLOSURE: In the past three years, Dr. Krumholz received expenses and/or personal fees from UnitedHealth, IBM Watson Health, Element Science, Aetna, Facebook, Massachusetts Medical Society, the Siegfried and Jensen Law Firm, Arnold and Porter Law Firm, Martin/Baughman Law Firm, F-Prime, and the National Center for Cardiovascular Diseases in Beijing. He is a co-founder of Refactor Health and HugoHealth, and had grants and/or contracts from the Centers for Medicare \& Medicaid Services, Medtronic, U.S. Food and Drug Administration, Johnson \& Johnson, Foundation for a SmokeFree World, State of Connecticut Department of Public Health, Agency for Healthcare Research and Quality, National Institutes of Health, American Heart Association, and the Shenzhen Center for Health Information. Dr. Murugiah works under contract with the Centers for Medicare \& Medicaid Services to support quality measurement programs. Dr. Lu is supported by the National Heart, Lung, and Blood Institute (K12HL138037) and the Yale Center for Implementation Science. She was a recipient of a research agreement, through Yale University, from the Shenzhen Center for Health Information for work to advance intelligent disease prevention and health promotion. Drs. Roy and Riley are consultants for the Institute for Healthcare Improvement. The other co-authors report no potential competing interests. 


\section{FIGURE LEGENDS}

\section{Figure 1.}

Title: Annual Estimated Prevalence of Short-Sleep Duration by Race and Ethnicity Among US Adults.

Legend: Data source is the National Health Interview Survey from years 2004 to 2018. Panel A displays overall estimates. Panel B displays estimates stratified by sex/gender. Panel C displays estimates stratified by household income level. All estimates are adjusted by age and US region. Brackets represent $95 \%$ confidence intervals. Short-sleep duration was defined as self-reported sleep duration of $\leq 6$ hours in a 24-hour period.

\section{Figure 2.}

Title: Annual Estimated Prevalence of Long-Sleep Duration by Race and Ethnicity Among US Adults.

Legend: Data source is the National Health Interview Survey from years 2004 to 2018. Panel A displays overall estimates. Panel B displays estimates stratified by sex/gender. Panel C displays estimates stratified by household income level. All estimates are adjusted by age and US region. Brackets represent $95 \%$ confidence intervals. Long-sleep duration was defined as self-reported sleep duration of $\geq 10$ hours in a 24 -hour period.

\section{Figure 3.}

Title: Relationship Between Age and Short- and Long-Sleep Duration by Race/Ethnicity Among US Adults. 
Legend: Data source is the National Health Interview Survey from years 2004 to 2018. Brackets represent $95 \%$ confidence intervals. Short-sleep duration was defined as self-reported sleep duration of $\leq 6$ hours in a 24-hour period. Long-sleep duration was defined as self-reported sleep duration of $\geq 10$ hours in a 24-hour period. Panels A and C show the estimated prevalence of each measure by race and ethnicity. Panels B and D show the estimated prevalence difference of each measure between Asian, Black, and Latino/Hispanic individuals with White individuals. 


\section{TABLES}

Table 1. Study Population Characteristics.

\begin{tabular}{|c|c|c|c|c|c|}
\hline & Asian Individuals & Black Individuals & $\begin{array}{l}\text { Latino/Hispanic } \\
\text { Individuals }\end{array}$ & White Individuals & All \\
\hline Sample size, $n[N=429,195]$ & 22,924 & 61,226 & 71,567 & 273,478 & 429,195 \\
\hline Age (years), median (IQR) & $42(31-55)$ & $42(29-56)$ & $38(28-51)$ & $48(33-62)$ & $46(31-60)$ \\
\hline $18-39$ years & $44.6(43.5,45.6)$ & $44.8(44.1,45.5)$ & $53.7(53.0,54.3)$ & $34.5(34.0,34.9)$ & $39.0(38.6,39.4)$ \\
\hline 40-64 years & $42.1(41.2,43.0)$ & $42.2(41.7,42.8)$ & $37.2(36.7,37.7)$ & $44.7(44.4,45.1)$ & $43.2(42.9,43.5)$ \\
\hline US Citizenship, \% (95\% CI) [n=428,343] & $69.7(68.5,70.8)$ & $95.3(94.9,95.6)$ & $65.2(64.3,66.1)$ & $98.5(98.4,98.5)$ & $91.8(91.5,92.0)$ \\
\hline \multicolumn{6}{|l|}{ Education level, \% (95\% CI) [n=426,934] } \\
\hline Less than high school & $9.4(8.8,10.1)$ & $16.8(16.3,17.3)$ & $35.3(34.5,36.0)$ & $9.5(9.3,9.7)$ & $14.1(13.8,14.4)$ \\
\hline High school diploma /GED & $26.8(26.5,27.1)$ & $30.3(29.7,30.9)$ & $26.5(26.0,27.0)$ & $26.8(26.5,27.1)$ & $26.6(26.4,26.9)$ \\
\hline Some college & $22.3(21.4,23.1)$ & $33.3(32.7,34.0)$ & $25.0(24.4,25.5)$ & $31.4(31.1,31.7)$ & $30.2(30.0,60.5)$ \\
\hline \multicolumn{6}{|l|}{ US region, ${ }^{\mathrm{b}} \%(95 \% \mathrm{CI})$} \\
\hline Northeast & $19.7(18.4,21.2)$ & $15.9(15.1,16.8)$ & $13.7(12.8,14.6)$ & $18.9(18.4,19.5)$ & $17.8(17.4,18.3)$ \\
\hline Midwest & $13.1(12.0,14.2)$ & $17.5(16.6,18.5)$ & $9.2(8.3,10.0)$ & $28.0(27.3,28.7)$ & $23.2(22.7,23.8)$ \\
\hline South & $22.0(20.6,23.5)$ & $58.2(56.8,59.6)$ & $36.6(35.1,38.1)$ & $33.8(33.0,34.5)$ & $36.5(35.8,37.1)$ \\
\hline West & $45.2(43.3,47.1)$ & $8.4(7.9,8.9)$ & $40.6(39.0,42.2)$ & $19.4(18.8,20.0)$ & $22.5(22.0,23.1)$ \\
\hline $\begin{array}{l}\text { Married or living with partner, \% (95\% CI) } \\
{[n=427,923]}\end{array}$ & $64.5(63.5,65.5)$ & $34.5(33.9,35.1)$ & $53.0(52.4,53.6)$ & $57.8(57.3,58.2)$ & $54.7(54.3,55.0)$ \\
\hline Employment status, \% (95\% CI) $[\mathrm{n}=428,865]$ & & & & & \\
\hline
\end{tabular}




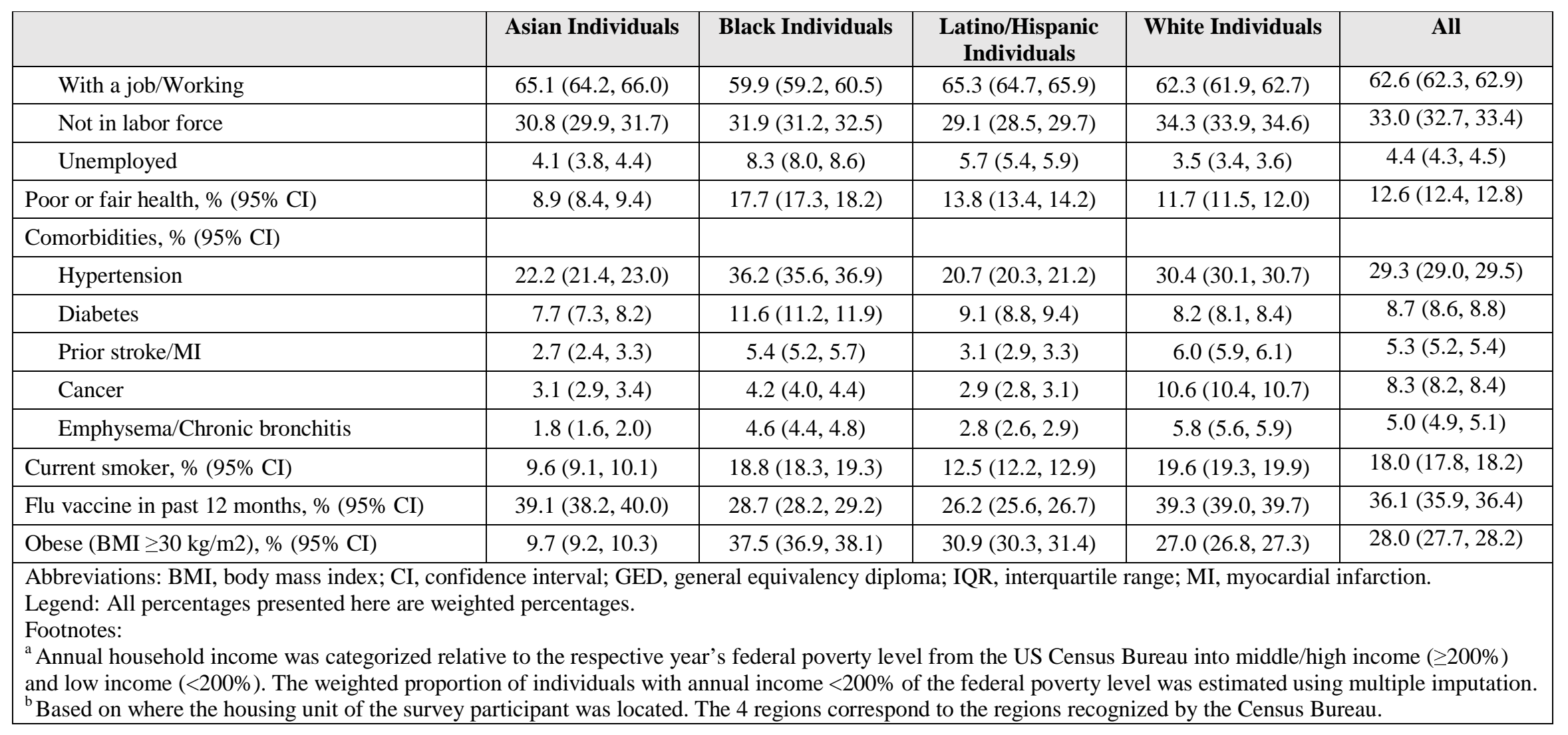


Table 2. Change in Short-Sleep Duration and Long-Sleep Duration Prevalence by Race and Ethnicity, 2004 to 2018.

\begin{tabular}{|c|c|c|c|c|c|c|c|c|c|}
\hline & \multicolumn{4}{|c|}{ Short Sleep } & \multicolumn{5}{|c|}{ Long Sleep } \\
\hline & $\begin{array}{c}\text { Asian } \\
\text { individuals } \\
\text { Percentage points } \\
(95 \% \mathrm{CI}), \mathrm{p} \\
\text { value }\end{array}$ & $\begin{array}{c}\text { Black } \\
\text { individuals } \\
\text { Percentage points } \\
(95 \% \mathrm{CI}), \mathrm{p} \\
\text { value }\end{array}$ & $\begin{array}{l}\text { Latino/Hispanic } \\
\text { individuals } \\
\text { Percentage points } \\
(95 \% \mathrm{CI}), \mathrm{p} \\
\text { value }\end{array}$ & $\begin{array}{c}\text { White } \\
\text { individuals } \\
\text { Percentage points } \\
\text { (95\% CI), p } \\
\text { value }\end{array}$ & $\begin{array}{c}\text { Asian } \\
\text { individuals } \\
\text { Percentage points } \\
(95 \% \mathrm{CI}), \mathrm{p} \\
\text { value }\end{array}$ & $\begin{array}{c}\text { Black } \\
\text { individuals } \\
\text { Percentage points } \\
(95 \% \mathrm{CI}), \mathrm{p} \\
\text { value }\end{array}$ & $\begin{array}{l}\text { Latino/Hispanic } \\
\text { individuals } \\
\text { Percentage points } \\
(95 \% \mathrm{CI}), \mathrm{p} \\
\text { value }\end{array}$ & $\begin{array}{c}\text { White } \\
\text { individuals } \\
\text { Percentage point } \\
\text { (95\% CI }), \mathrm{p} \\
\text { value }\end{array}$ & 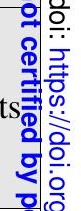 \\
\hline $\begin{array}{l}\text { Absolute change in } \\
\text { prevalence, 2004- } \\
2018 \\
\end{array}$ & & & & & & & & & \\
\hline All & $\begin{array}{l}+1.55(-2.98 \\
+6.07), 0.50\end{array}$ & $\begin{array}{l}+6.40(+3.33 \\
+9.46),<0.001 \\
\end{array}$ & $\begin{array}{l}+6.60(+4.04, \\
+9.15),<0.001 \\
\end{array}$ & $\begin{array}{l}+3.20(+2.04, \\
+4.36),<0.001 \\
\end{array}$ & $\begin{array}{l}-0.05(-1.76 \\
+1.65), 0.95 \\
\end{array}$ & $\begin{array}{l}-1.23(-2.68 \\
+0.21), 0.10 \\
\end{array}$ & $\begin{array}{c}-1.42(-2.51,- \\
0.32), 0.01 \\
\end{array}$ & $\begin{array}{l}+0.22(-0.24, \text { ब } \\
+0.68), 0.35 \text { बे }\end{array}$ & 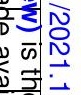 \\
\hline Women & $\begin{array}{l}+3.98(-2.32 \\
+10.27), 0.22\end{array}$ & $\begin{array}{r}+7.08(+3.11, \\
+11.05),<0.001\end{array}$ & $\begin{array}{c}+4.43(+1.12 \\
+7.74), 0.01 \\
\end{array}$ & $\begin{array}{l}+3.68(+2.11 \\
5.25),<0.001\end{array}$ & $\begin{array}{l}-0.74(-3.38 \\
+1.89), 0.58\end{array}$ & $\begin{array}{l}-0.50(-2.32 \\
+1.31), 0.587\end{array}$ & $\begin{array}{c}-2.03(-3.42,- \\
0.64), 0.004\end{array}$ & $\begin{array}{c}+0.16(-0.43, \text {, } \\
0.74), 0.60\end{array}$ & 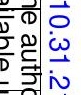 \\
\hline Men & $\begin{array}{c}-0.88(-7.47 \\
5.70), 0.79 \\
\end{array}$ & $\begin{array}{l}+5.66(+1.18 \\
+10.13), 0.01\end{array}$ & $\begin{array}{r}+8.74(+4.90 \\
+12.57),<0.001 \\
\end{array}$ & $\begin{array}{c}+2.68(+1.07 \\
4.29), 0.001 \\
\end{array}$ & $\begin{array}{l}+0.54(-1.52 \\
+2.60), 0.61 \\
\end{array}$ & $\begin{array}{c}-2.13(-4.21,- \\
0.04), 0.05 \\
\end{array}$ & $\begin{array}{l}-0.81(-2.45 \\
+0.84), 0.34 \\
\end{array}$ & $\begin{array}{l}+0.28\left(-0.42, \frac{}{\mathbb{\Phi}}\right. \\
+0.97), 0.44\end{array}$ & $\begin{array}{l}0 \\
\text { ton } \\
\text { ch } \\
0 \\
0 \\
0\end{array}$ \\
\hline Low income & $\begin{array}{c}+3.09(-7.09 \\
13.28), 0.55\end{array}$ & $\begin{array}{c}+8.16(+3.62, \\
+12.69),<0.001\end{array}$ & $\begin{array}{c}+6.57(+2.80 \\
+10.34),<0.001\end{array}$ & $\begin{array}{l}+5.00(+2.61, \\
+7.38),<0.001 \\
\end{array}$ & $\begin{array}{l}-2.14(-6.74 \\
+2.47), 0.36\end{array}$ & $\begin{array}{l}-2.09(-4.61 \\
+0.42), 0.10\end{array}$ & $\begin{array}{l}-1.37(-2.98 \\
+0.23), 0.09\end{array}$ & $\begin{array}{l}+0.71(-0.41, \\
+1.91), 0.25\end{array}$ & 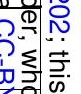 \\
\hline Mid/high income & $\begin{array}{l}+0.96(-4.25 \\
+6.17), 0.72\end{array}$ & $\begin{array}{c}+4.97(+0.76 \\
+9.19), 0.02\end{array}$ & $\begin{array}{l}+6.03(+2.33 \\
+9.74), 0.001 \\
\end{array}$ & $\begin{array}{l}+2.93(+1.59 \\
+4.26),<0.001 \\
\end{array}$ & $\begin{array}{l}+0.83(-0.74 \\
+2.40), 0.30\end{array}$ & $\begin{array}{l}-0.50(-2.16 \\
+1.15), 0.55\end{array}$ & $\begin{array}{l}-1.28(-2.86 \\
+0.30), 0.11\end{array}$ & $\begin{array}{l}+0.18\left(-0.34, \frac{1}{2}\right. \\
+0.69), 0.50\end{array}$ & 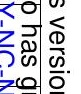 \\
\hline $\begin{array}{l}\text { Difference with } \\
\text { White, } 2004\end{array}$ & & & & & & & & & 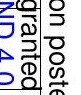 \\
\hline Overall & $\begin{array}{l}+3.56(+0.13 \\
+7.00), 0.04\end{array}$ & $\begin{array}{r}+7.49(+5.46 \\
+9.53),<0.001\end{array}$ & $\begin{array}{l}-0.87(-2.64 \\
+0.89), 0.33\end{array}$ & - & $\begin{array}{l}-1.05(-2.52 \\
+0.42), 0.16\end{array}$ & $\begin{array}{r}+2.88(+1.78 \\
+3.98),<0.001 \\
\end{array}$ & $\begin{array}{c}+1.06(+0.30 \\
+1.82), 0.01\end{array}$ & - & 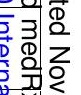 \\
\hline Women & $\begin{array}{l}+2.70(-2.09 \\
+7.50), 0.27\end{array}$ & $\begin{array}{c}+8.70(+5.99 \\
+11.42),<0.001 \\
\end{array}$ & $\begin{array}{l}+0.46(-1.78 \\
+2.70), 0.69\end{array}$ & - & $\begin{array}{l}-0.27(-2.53 \\
+1.99), 0.81\end{array}$ & $\begin{array}{l}+2.46(+1.14 \\
+3.78),<0.001\end{array}$ & $\begin{array}{l}+1.48(+0.41 \\
+2.55), 0.01\end{array}$ & - & $\begin{array}{ll}x \\
x \\
x\end{array}$ \\
\hline Men & $\begin{array}{l}+4.27(-0.74 \\
+9.27), 0.10\end{array}$ & $\begin{array}{l}+6.14(+3.13 \\
+9.15),<0.001\end{array}$ & $\begin{array}{l}-2.29(-4.79 \\
+0.22), 0.07\end{array}$ & - & $\begin{array}{c}-1.89(-3.66,- \\
0.12), 0.04\end{array}$ & $\begin{array}{l}+3.38(+1.68 \\
+5.08),<0.001\end{array}$ & $\begin{array}{l}+0.64(-0.46 \\
+1.74), 0.26\end{array}$ & - & \\
\hline Low income & $\begin{array}{l}+1.49(-6.31 \\
+9.30), 0.71\end{array}$ & $\begin{array}{l}+1.51(-1.55 \\
+4.57), 0.33\end{array}$ & $\begin{array}{l}-5.95(-8.57,- \\
3.34),<0.001\end{array}$ & - & $\begin{array}{l}-0.38(-4.62 \\
+3.86), 0.86\end{array}$ & $\begin{array}{c}+3.44(+1.47 \\
+5.40),<0.001\end{array}$ & $\begin{array}{l}-0.40(-1.62 \\
+0.82), 0.52\end{array}$ & - & \\
\hline Mid/high income & $\begin{array}{l}+4.15(+0.25 \\
+8.05), 0.04\end{array}$ & $\begin{array}{c}+10.24(+7.33 \\
+13.15),<0.001 \\
\end{array}$ & $\begin{array}{l}+1.62(-1.10 \\
+4.34), 0.24\end{array}$ & - & $\begin{array}{c}-1.51(-2.70,- \\
0.32), 0.01\end{array}$ & $\begin{array}{l}+1.44(+0.24 \\
+2.64), 0.02 \\
\end{array}$ & $\begin{array}{l}+0.98(-0.17 \\
+2.14), 0.10\end{array}$ & - & לֶ. \\
\hline $\begin{array}{l}\text { Difference with } \\
\text { White, } 2018\end{array}$ & & & & & & & & & 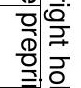 \\
\hline Overall & $\begin{array}{l}+1.91(-1.26 \\
+5.07), 0.24\end{array}$ & $\begin{array}{l}+10.69(+8.12 \\
+13.26),<0.001\end{array}$ & $\begin{array}{l}+2.52(+0.34 \\
+4.71), 0.02\end{array}$ & - & $\begin{array}{c}-1.32(-2.30,- \\
0.34), 0.01\end{array}$ & $\begin{array}{c}+1.42(+0.37 \\
+2.47), 0.01\end{array}$ & $\begin{array}{l}-0.58(-1.49 \\
+0.34), 0.22\end{array}$ & - & \\
\hline Women & $\begin{array}{l}+3.00(-1.38 \\
+7.38), 0.18\end{array}$ & $\begin{array}{l}+12.10(+8.81 \\
+15.40),<0.001\end{array}$ & $\begin{array}{l}+1.21(-1.69 \\
+4.11), 0.41\end{array}$ & - & $\begin{array}{l}-1.17(-2.65 \\
+0.30), 0.12 \\
\end{array}$ & $\begin{array}{c}+1.80(+0.42 \\
+3.18), 0.01\end{array}$ & $\begin{array}{l}-0.70(-1.77 \\
0.36), 0.197\end{array}$ & - & \\
\hline
\end{tabular}




\begin{tabular}{|c|c|c|c|c|c|c|c|c|c|}
\hline & \multicolumn{4}{|c|}{ Short Sleep } & \multicolumn{4}{|c|}{ Long Sleep } & \\
\hline & \begin{tabular}{|c|} 
Asian \\
individuals \\
Percentage points \\
(95\% CI), p \\
value \\
\end{tabular} & $\begin{array}{c}\text { Black } \\
\text { individuals } \\
\text { Percentage points } \\
(95 \% \mathrm{CI}), \mathrm{p} \\
\text { value }\end{array}$ & $\begin{array}{l}\text { Latino/Hispanic } \\
\text { individuals } \\
\text { Percentage points } \\
(95 \% \mathrm{CI}), \mathrm{p} \\
\text { value }\end{array}$ & $\begin{array}{c}\text { White } \\
\text { individuals } \\
\text { Percentage points } \\
(95 \% \mathrm{CI}), \mathrm{p} \\
\text { value }\end{array}$ & $\begin{array}{c}\text { Asian } \\
\text { individuals } \\
\text { Percentage points } \\
(95 \% \mathrm{CI}), \mathrm{p} \\
\text { value }\end{array}$ & $\begin{array}{c}\text { Black } \\
\text { individuals } \\
\text { Percentage points } \\
(95 \% \mathrm{CI}), \mathrm{p} \\
\text { value } \\
\end{array}$ & $\begin{array}{c}\text { Latino/Hispanic } \\
\text { individuals } \\
\text { Percentage points } \\
(95 \% \mathrm{CI}), \mathrm{p} \\
\text { value } \\
\end{array}$ & $\begin{array}{c}\text { White } \\
\text { individuals } \\
\text { Percentage point } \\
(95 \% \mathrm{CI}), \mathrm{p} \\
\text { value }\end{array}$ & 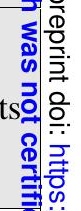 \\
\hline Men & $\begin{array}{c}+0.70(-3.87 \\
+5.28), 0.76\end{array}$ & $\begin{array}{l}+9.12(+5.44 \\
+12.79),<0.001\end{array}$ & $\begin{array}{c}+3.77(+0.45 \\
+7.09), 0.03\end{array}$ & - & $\begin{array}{c}-1.63(-2.88,- \\
0.37), 0.01\end{array}$ & $\begin{array}{l}+0.98(-0.42 \\
+2.37), 0.17\end{array}$ & $\begin{array}{l}-0.44(-1.85 \\
+0.96), 0.54\end{array}$ & - & \\
\hline Low income & $\begin{array}{l}-0.41(-7.38 \\
+6.56), 0.91\end{array}$ & $\begin{array}{c}+4.67(+0.56 \\
+8.78), 0.03\end{array}$ & $\begin{array}{c}-4.38(-8.00,- \\
0.76), 0.02\end{array}$ & - & $\begin{array}{c}-3.23(-5.38,- \\
1.08), 0.003\end{array}$ & $\begin{array}{l}+0.63(-1.34 \\
+2.60), 0.53\end{array}$ & $\begin{array}{c}-2.48(-4.07,- \\
0.89), 0.002\end{array}$ & - & \\
\hline Mid/high income & $\begin{array}{l}+2.18(-1.52 \\
+5.89), 0.25\end{array}$ & $\begin{array}{l}+12.29(+8.97 \\
+15.61),<0.001\end{array}$ & $\begin{array}{l}+4.73(+1.88 \\
+7.57), 0.001\end{array}$ & - & $\begin{array}{l}-0.85(-2.00 \\
+0.30), 0.15\end{array}$ & $\begin{array}{l}+0.76(-0.49 \\
+2.01), 0.23\end{array}$ & $\begin{array}{l}-0.47(-1.66 \\
+0.72), 0.44\end{array}$ & - & \\
\hline $\begin{array}{l}\text { Absolute change in } \\
\text { difference with } \\
\text { White, 2004-2018 }\end{array}$ & & & & & & & & & \\
\hline Overall & $\begin{array}{l}-1.65(-6.32 \\
+3.02), 0.50\end{array}$ & $\begin{array}{l}+3.20(-0.08 \\
+6.47), 0.06\end{array}$ & $\begin{array}{l}+3.40(+0.59 \\
+6.20), 0.02\end{array}$ & - & $\begin{array}{l}-0.27(-2.04 \\
+1.49), 0.76\end{array}$ & $\begin{array}{l}-1.46(-2.98 \\
+0.06), 0.06\end{array}$ & $\begin{array}{c}-1.64(-2.83,- \\
0.45), 0.007\end{array}$ & - & \\
\hline Women & $\begin{array}{l}+0.30(-6.19 \\
+6.79), 0.93\end{array}$ & $\begin{array}{l}+3.40(-0.87 \\
+7.67), 0.12\end{array}$ & $\begin{array}{l}+0.75(-2.91 \\
+4.42), 0.69\end{array}$ & - & $\begin{array}{l}-0.90(-3.60 \\
+1.80), 0.51\end{array}$ & $\begin{array}{l}-0.66(-2.57 \\
+1.25), 0.50\end{array}$ & $\begin{array}{c}-2.19(-3.70,- \\
0.67), 0.005\end{array}$ & - & \\
\hline Men & $\begin{array}{l}-3.56(-10.34 \\
+3.22), 0.30\end{array}$ & $\begin{array}{l}+2.98(-1.78 \\
+7.73), 0.22\end{array}$ & $\begin{array}{l}+6.06(+1.90 \\
+10.22), 0.004\end{array}$ & - & $\begin{array}{l}+0.26(-1.91 \\
+2.44), 0.813\end{array}$ & $\begin{array}{c}-2.40(-4.60,- \\
0.20), 0.03\end{array}$ & $\begin{array}{l}-1.08(-2.87 \\
+0.70), 0.24\end{array}$ & - & \\
\hline Low income & $\begin{array}{l}-1.90(-12.36 \\
+8.56) 0.72\end{array}$ & $\begin{array}{l}+3.16(-1.97 \\
+8.28), 0.23\end{array}$ & $\begin{array}{l}+1.57(-2.89 \\
+6.04), 0.49\end{array}$ & - & $\begin{array}{l}-2.85(-7.60 \\
+1.91), 0.24\end{array}$ & $\begin{array}{c}-2.81(-5.59,- \\
0.02), 0.05\end{array}$ & $\begin{array}{c}-2.08(-4.09,- \\
0.08), 0.04\end{array}$ & - & \\
\hline Mid/high income & $\begin{array}{l}-1.97(-7.35 \\
+3.41) 0.47\end{array}$ & $\begin{array}{l}+2.05(-2.37 \\
+6.47), 0.36\end{array}$ & $\begin{array}{l}+3.11(-0.83 \\
+7.04), 0.12\end{array}$ & - & $\begin{array}{l}+0.66(-1.00 \\
+2.31), 0.44\end{array}$ & $\begin{array}{l}-0.68(-2.41 \\
+1.05), 0.44\end{array}$ & $\begin{array}{l}-1.46(-3.12 \\
+0.21), 0.09\end{array}$ & - & \\
\hline \multicolumn{10}{|c|}{ 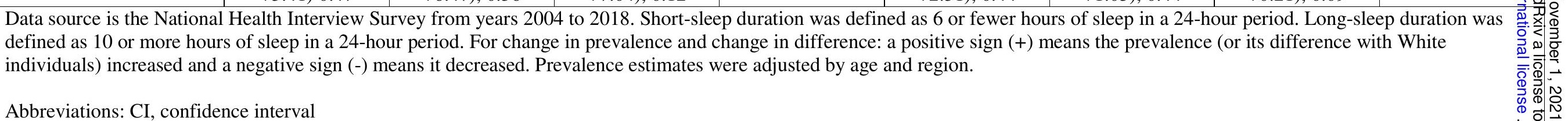 } \\
\hline
\end{tabular}

Abbreviations: CI, confidence interval 


\section{FIGURES}

Figure 1.

A.

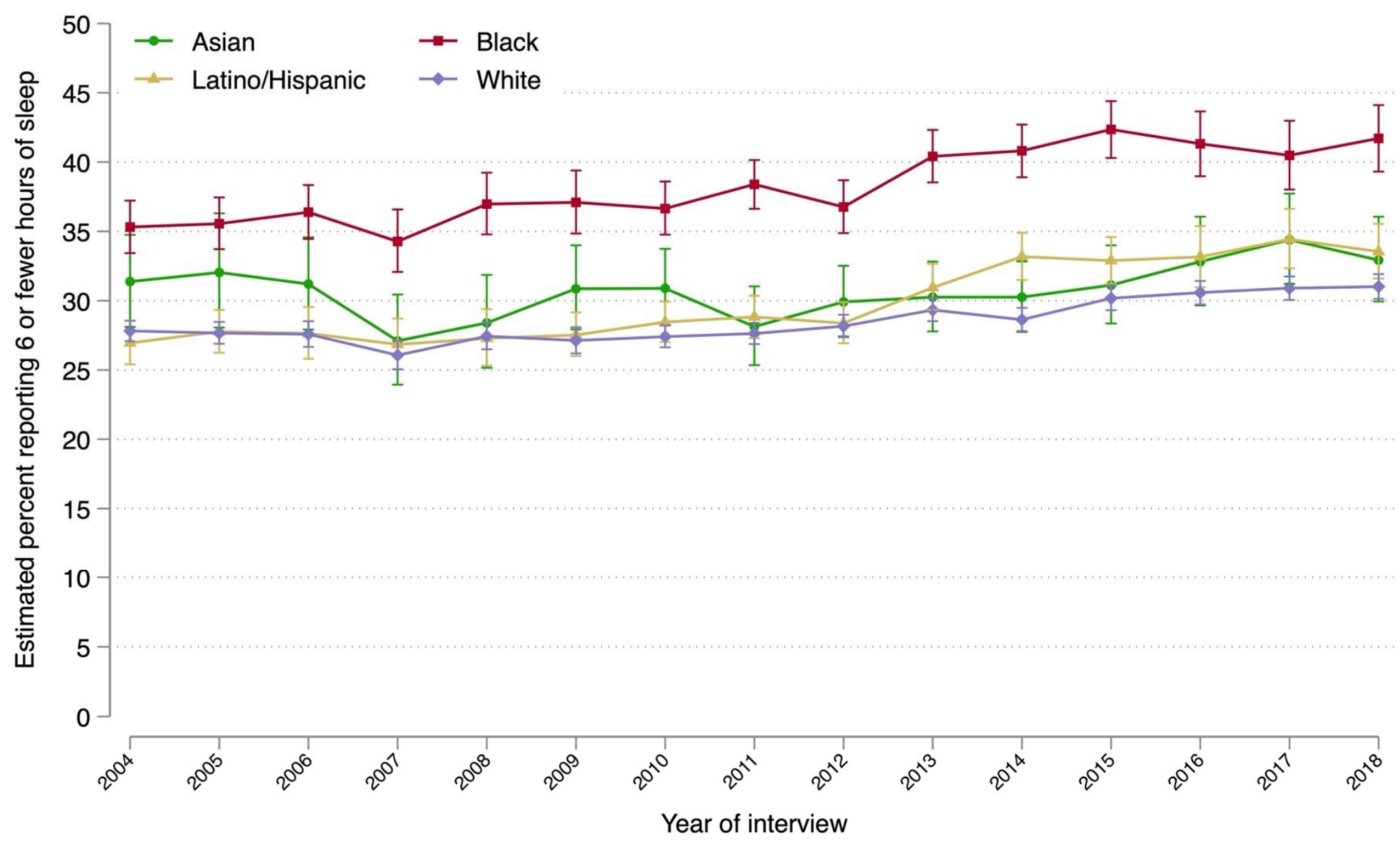


B.
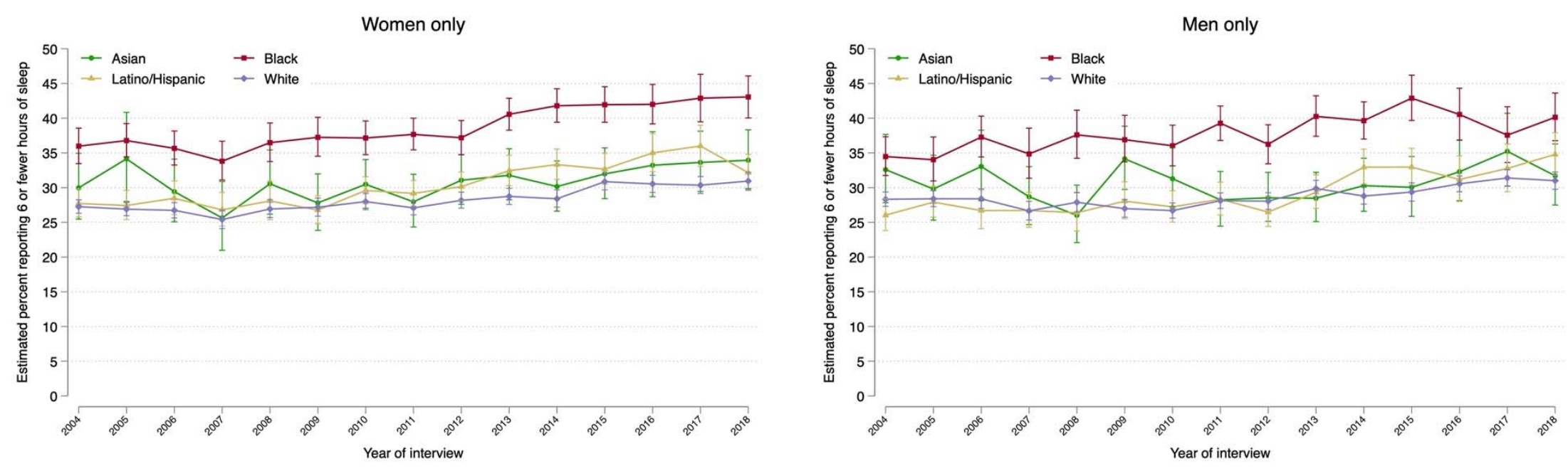

C.
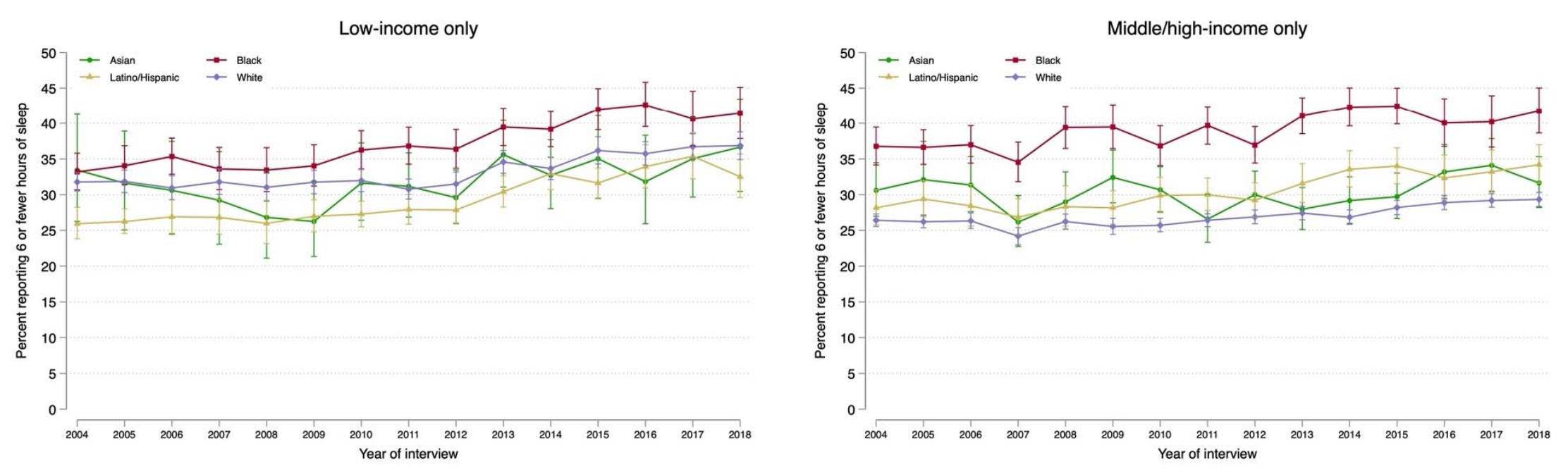


\section{Figure 2.}

A.

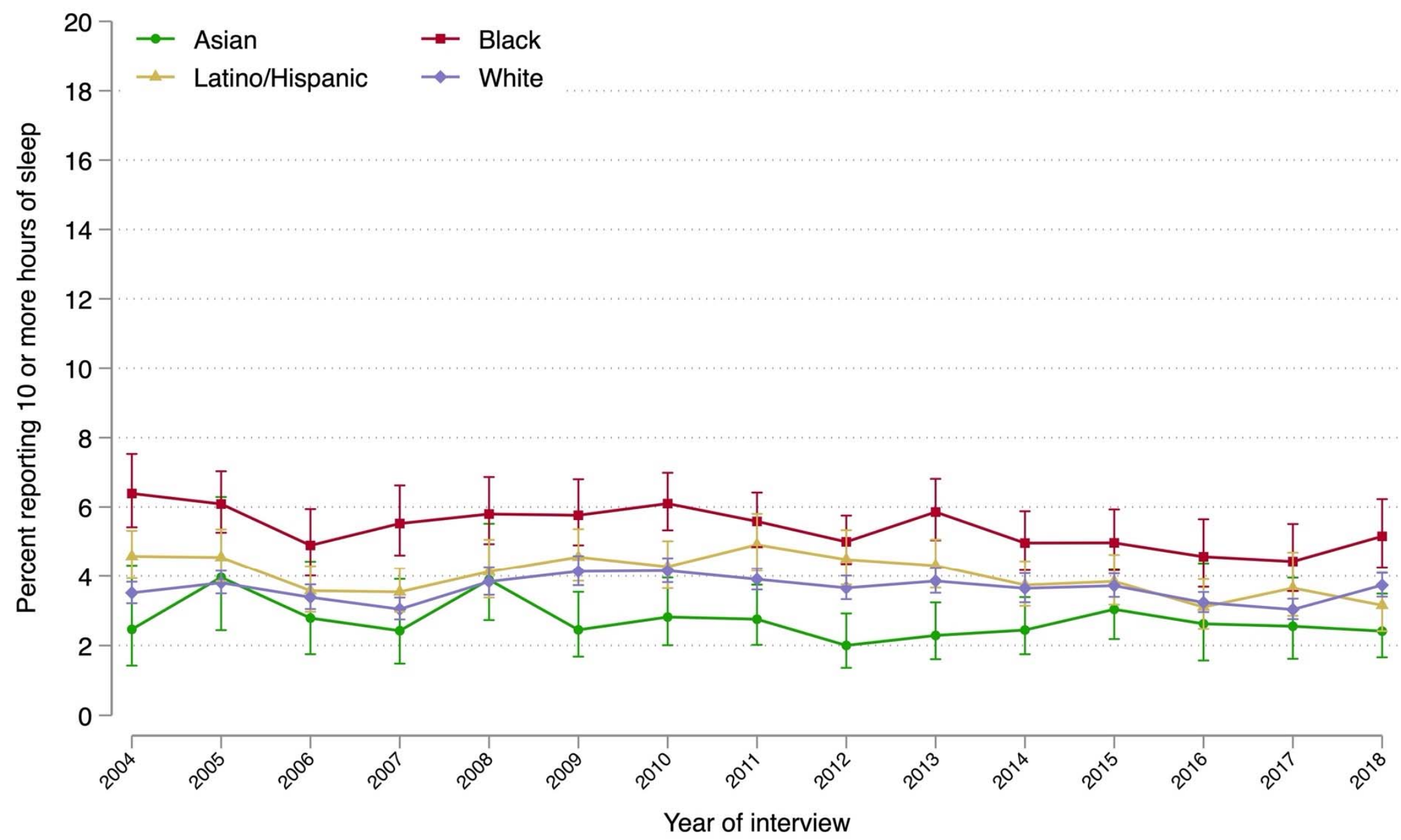


B.
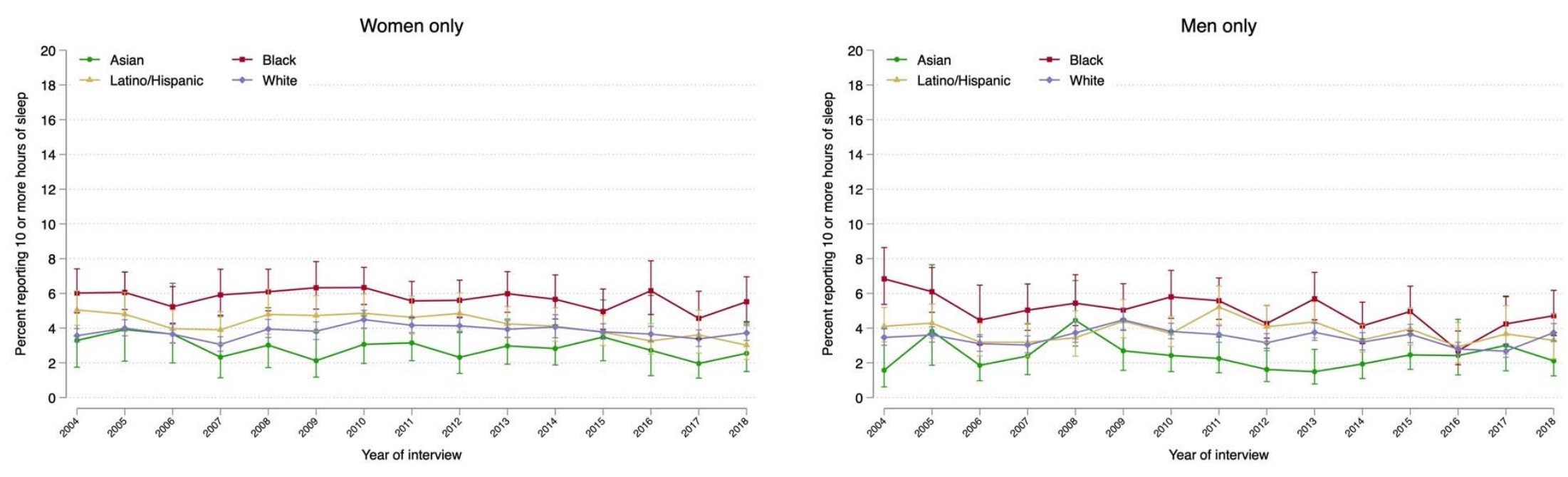

C.
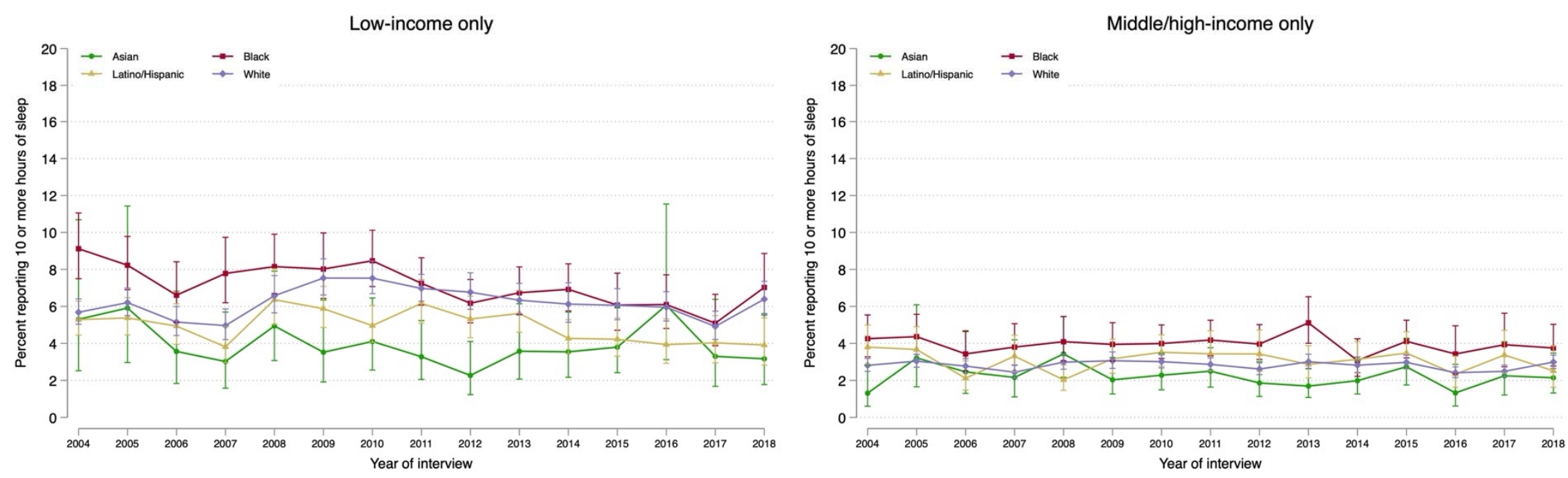


\section{Figure 3.}

A.

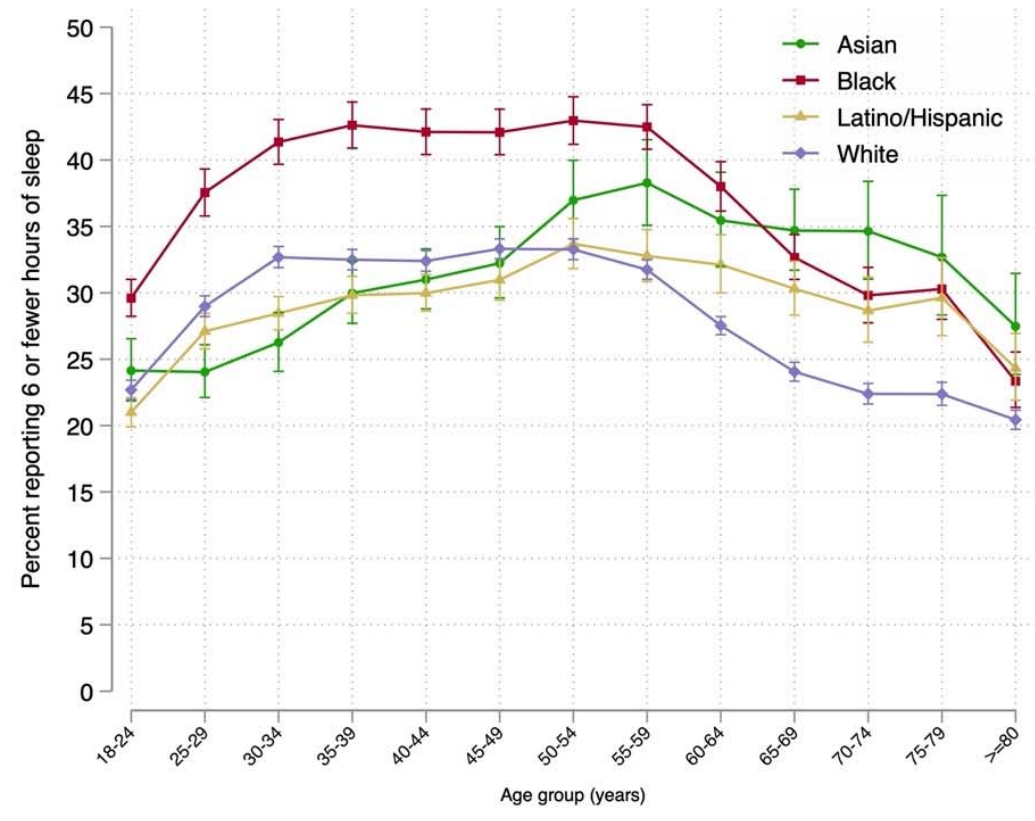

B.

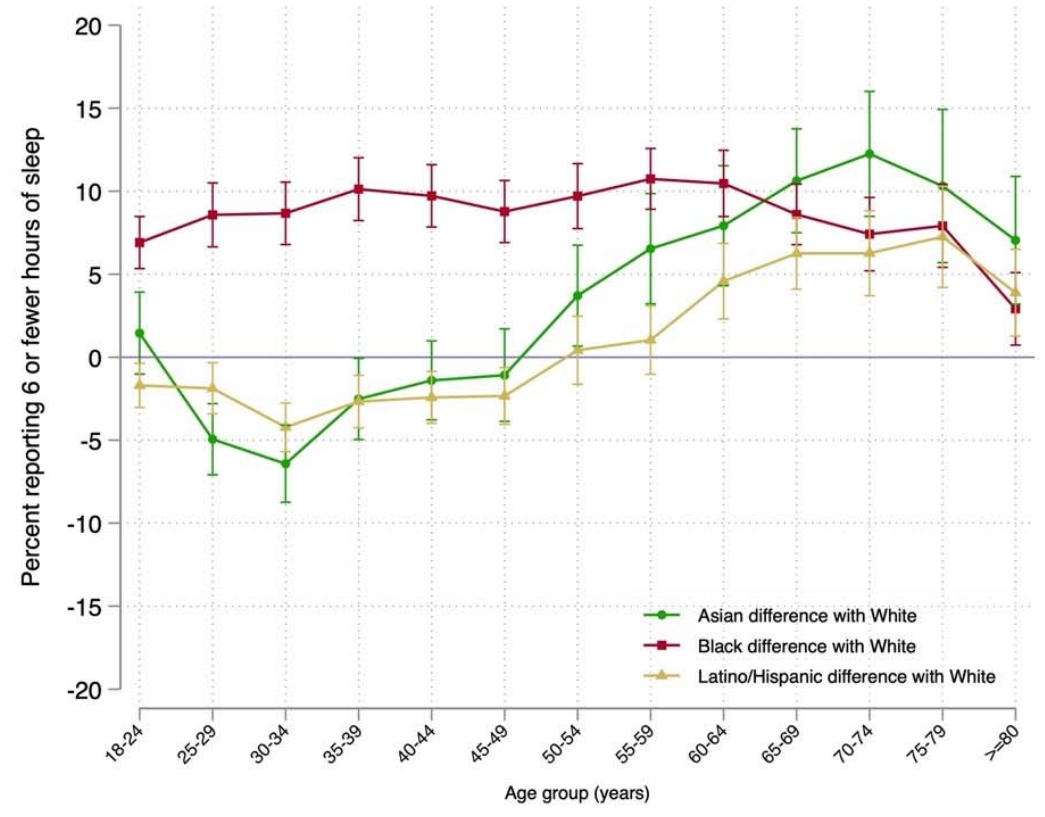


C.

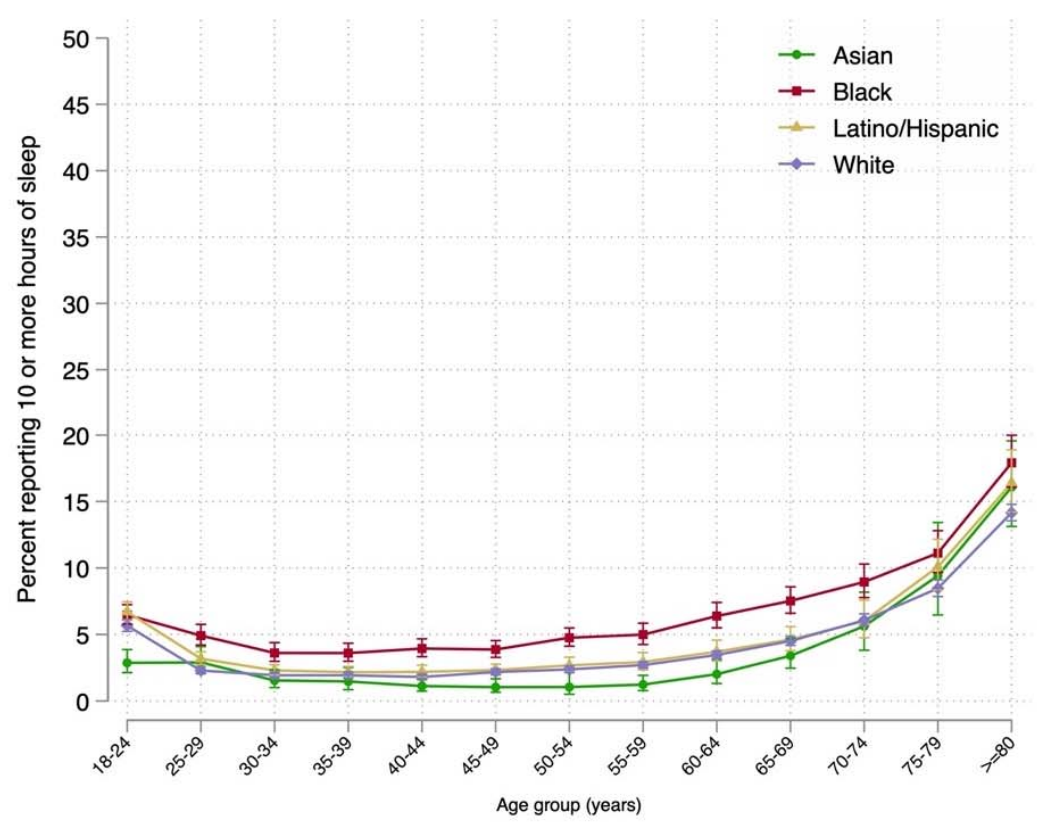

D.

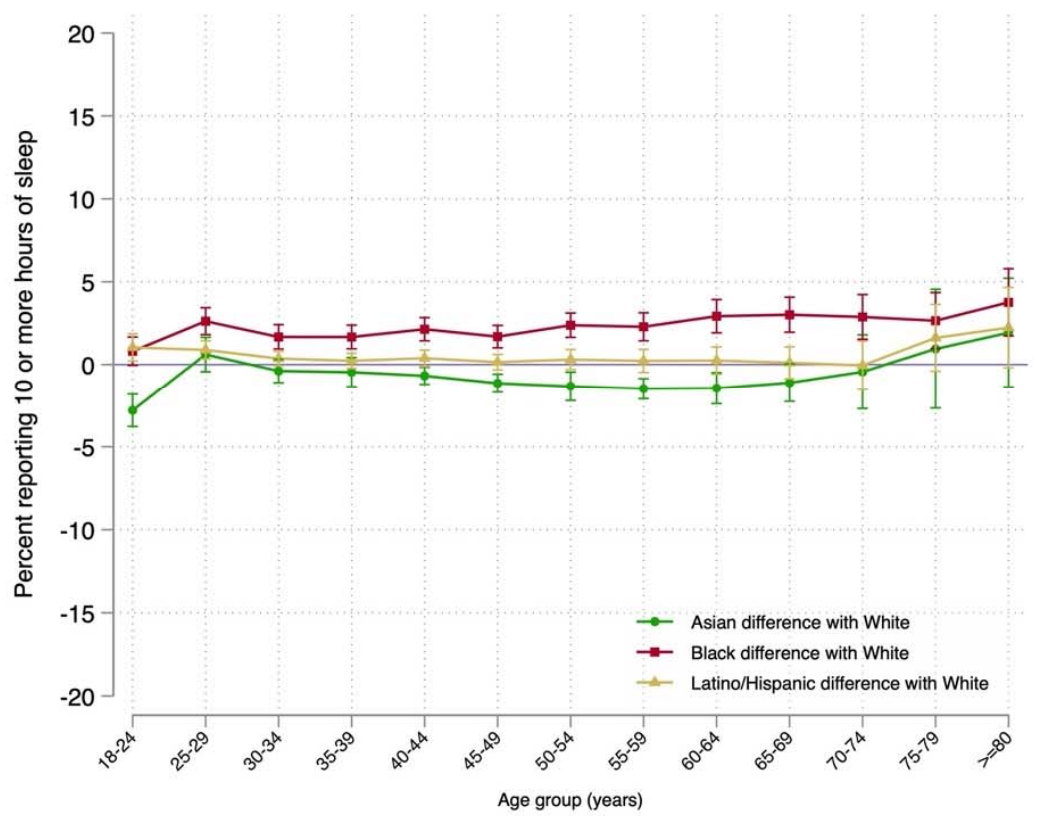

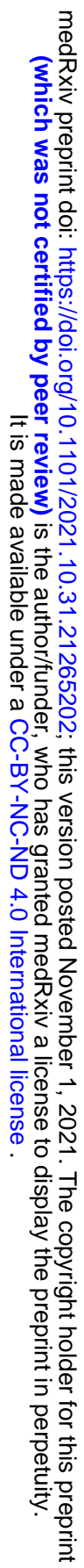

37 